\title{
SARS-struck nations step up surveillance efforts
}

Only two weeks after the World Health Organization (WHO) declared Canada free of severe acute respiratory syndrome (SARS), staff members at a Toronto hospital missed warning symptoms in a feverish 96-year-old man. That slip was enough to revive a full-scale SARS outbreak in the city. As of 11 June, Canada had 73 active cases, with a death toll of 32. The world death toll now stands at 789 , with 8,435 probable cases, but the WHO estimates that the global outbreak is probably past its peak.

Canada's "crude containment strategy" and the resulting crisis underscores the need for heightened surveillance and control measures against SARS and other infectious diseases, says Prabhat Jha, an epidemiologist at the University of Toronto.

Having learned their lesson the hard way, many SARS-afflicted nations are scrambling to upgrade their public health systems to include early detection and vigilant quarantine. At the recent World Health Assembly, member nations also passed two resolutions that grant the WHO new powers to more effectively monitor emerging epidemics.

"[Disease] surveillance has to start from the ground, so the best thing to do is think global and act local," says Iain Simpson, a spokesman for the WHO.

At the regional level, SARS-hit cities have launched extensive clean-up campaigns. In Beijing, new bylaws have made the age-old habit of spitting punishable by hefty fines. Residents there are now required to spit into small bags. In Hong Kong, officials are considering cash rewards for 'hygiene informants' who rat out neighbors that spit, litter or keep pets.

Federal governments are also revamping their public health systems. The Chinese government, which was chastised for withholding information about early SARS cases, plans to build a new Emergency Response Bureau to coordinate the country's response to outbreaks. Vietnam, praised worldwide for its swift surveillance and quarantine efforts, says it will in each of its 61 provinces appoint epidemic prevention committees armed with new medical equipment.

On the global front, Jong-Wook Lee, the new director general of the WHO, says that a key objective during his tenure will be to improve global health surveillance and data management, with $90 \%$ of resources devoted to building surveillance capacity at national and regional levels. One of the two new WHO resolutions, to be formally approved in 2005, enables the WHO to communicate around the clock with countries, issue global alerts for international health threats and use nonofficial sources of information such as reports from nongovernmental organizations and the media.

By September, the WHO and the World Economic Forum's Global Health Initiative plan to boost surveillance efforts-such as enforced case reporting-by raising $\$ 100$ million from corporations with investments in Asia. The Asian Development Bank is also expected to offer grants and loans of nearly $\$ 30$ million to help its members cope with SARS.

The WHO's new resolutions represent a huge advance, says Barry Bloom, dean of the Harvard School of Public Health. What's needed, he adds, is a global network-similar to the WHO's Global Influenza Program-to monitor all emerging infections of the world, rather than address them one at a time.

SARS experts will discuss that and other innovative control strategies mid-June in Kuala Lumpur. Such meetings may finally trigger much-needed cooperation between epidemiologists from both developed and developing countries, says Jha. It may also bridge the gap between epidemiologists and scientists from all other disciplines.

"Lab scientists and public health people need to work together," Jha says. "Basic scientists could benefit from epidemiological data that is significant to their research and epidemiologists could benefit from basic scientific

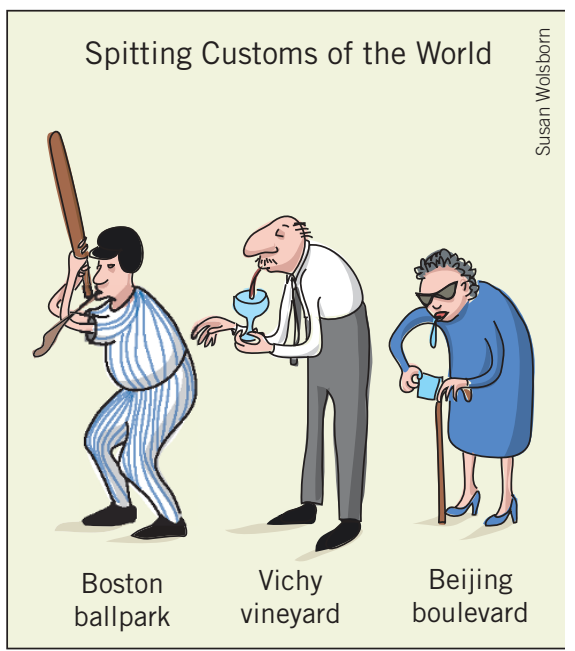

tools like DNA assays."

Clinical researchers have already seen success from their collaborations, including the agreement between Roche Diagnostics and the Genome Institute of Singapore to develop a SARS detection kit by the end of July. Scientists in Hong Kong and mainland China also jointly announced that they will soon test a potential SARS vaccine on animals.

Allocating more resources into exchanging knowledge and making global health an economic priority will dramatically improve the world's chances of fighting emerging infectious diseases, says Jha. "It's an easy fix under WHO leadership."

Paroma Basu, New York

\section{China enlists traditional meds for SARS}

Experts in traditional Chinese medicine (TCM) are calling for the use of ancient Chinese remedies in combination with Western treatments to stem severe acute respiratory syndrome (SARS).

Since the beginning of the SARS outbreak, TCM practitioners have treated hundreds of SARS patients in Beijing and Guangdong with acupuncture and herbal remedies alongside Western steroids and antivirals, says Beijing's vice-mayor Zhang Mao.

The experts designed a new herbal cocktail to fortify the immune systems of SARS patients. Included in the formula is Radix isatidis seu baphicacanthi, an herbal root often used to fight infectious diseases, says Grant Zhang, assistant professor of integrative medicine at the University of Maryland.

TCM specialists interpret SARS symptoms as a kind of 'wetness' that disrupts the yin-yang, or negative-positive, balance of the body. Clinical observations show that a combined treatment approach is beneficial to patients, Zhang says. Because the treatments are individualized for each patient, however, clinical data are scarce.

The US National Institute of Allergy and Infectious Diseases, which is screening compounds to treat SARS, is including herbal candidates in its repertoire. Officials have screened two herbal candidates thus far, with others in line, says Catherine Laughlin, chief of the agency's virology branch.

Paroma Basu, New York 